\title{
Considerations in Breeding and Selection for Certain Important Characters in Arabica Coffee(Coffea Arabica L.)
}

\author{
Kalifa Nasiro Demelash Teferi \\ Ethiopian Institute of Agricultural Research, Jimma Agricultural Research Center. P.O. Box 192, Jimma, \\ Ethiopia
}

\begin{abstract}
A Review Article
\section{Abstract}

Implications of the results in breeding programmes are discussed. A breeding scheme is proposed aimed at developing compact high yielding coffee varieties with good quality which also combine resistance to the two main diseases of arabica coffee, coffee berry disease and coffee rust. The breeding scheme entails either development of hybrid varieties, or a programme of further selection to derive seed varieties. Important features of such a scheme are, 1) the use of information on genetic basis of variation for certain characters in planning hybridization programmes and, 2) a drastically reduced breeding cycle per generation as a result of basing selection, within each generation, on fairly young coffee trees.
\end{abstract}

Keywords: Coffea arabica, coffee yield, compact growth, coffee quality, disease resistance

DOI: $10.7176 / \mathrm{JBAH} / 9-11-03$

Publication date:June $30^{\text {th }} 2019$

\section{Introduction}

Arabica coffee being a perennial tree crop has a relatively long juvenile period. Breeding programmes in such a crop are of necessity long term. Because the species is autogamous, the present commercial cultivars, having been derived as single tree selections, show a high degree of true breeding and are therefore propagated mostly by seed. Asexual propagation by means of by rooting softwood cuttings is possible (van der Vossen \& Op de Laak, 1976; van der Vossen et al., 1976) and can be especially useful for breeding purposes. Among the main goals of most current breeding programmes, including the one in progress at the Jimma Agricultural Research centre (JARC) are improved yield coupled with quality and disease resistance.

In order to achieve these goals, breeding procedures have to involve hybridization among different varieties selected for certain desirable attributes which they carry. Planning of such a programme and indications of immediate consequences of selection is best understood against a background of information relating to the mode of inheritance, and the amount of genetic variation among the available genotypes, for the character in question (Fernie, L.M., 1961).

For instance, regarding the performance of $F 1$ hybrids, intense hybrid vigour may have, especially in a perennial crop, important consequences as far as breeding and selection for the given character is concerned (Srinivasan, CS., 1980). On the other hand, when considering an F2 population, not only the number of genes or groups of tightly linked genes segregating but also the effects of these genes, will have a great influence on the effect of selection applied to a certain character. With 1 gene segregating for example, selection of $25 \%$ of $F 2$ individuals at either end of the scale will lead to immediate fixation of homozygous types in the next generation. With 5 independent genes segregating however, only one individual in a population of 1,024 will be homozygous for each of the extreme genotypes. The probability of fixation of such a genotype in the next generation is very small and especially so, if the gene effects are also masked by the external environment. Therefore, with characters controlled by a small number of gene loci, each with fairly large effects, the segregation pattern in the F2 is often clear enough to allow genotypes to be categorized according to the combination of genes they carry. The distribution of phenotypes will of course vary depending on the presence of dominance and/or epistatic effects as well as linkage between genes controlling the character (Griffing, J.B., 1956).

Aids in selection in form of special techniques applied in judging the actual genetic worth of individual plants have to be given more attention, as these are extremely useful in early generation evaluation. Their development also depends on having detailed information on the genetic control of a character as well as the interrelationship between the character in question and other characters. Such aids in selection have been emphasized throughout this review, and no doubt, are essential if reasonable progress has to be made in a breeding programme of perennial crop with a long juvenile period, where time are an extremely important element (Baker, R.J., 1978).

In this review, information derived mainly from the basis for considering some of the above aspects in breeding and selection programmes for each of the characters given below.

\section{Yield improvement}

Selection of parental genotypes may depend on making crosses between all or most of the selected parental varieties, which will also include the best varieties currently in use. This type of crossing scheme has two main 
advantages:

1) it will enable evaluation of combining ability of the different genotypes not only for yield, but also for other equally important attributes which the different genotypes may carry (e.g. quality, growth habit and disease resistance) all at the same time,

2) it can be used for studying the genetic control of the various characters in that population.

It is often useful to realize that crosses between high yielding genotypes may not always give rise to progenies that are superior to both parents, unless the parents differ considerably with respect to certain growth and yield characters. In this review for example, such outstanding hybrids are those of crosses involving Padang and SL28 or Padang and SL34 (see Table1). It is even possible also, for some very unproductive variety when crossed with a high yielding variety, to give rise to an F1 hybrid that is superior to the more productive variety. For example Laurina with Padang and Laurina with K7 in the same table. Laurina in this case, is outstanding for the number of bearing primaries but has also very short internodes. It is possible that recombinations of these and other characters when Laurina is crossed to the better performing parents are responsible for the superiority of the F1 hybrids. It is clear from Table 1, hybrid vigour or heterosis in general, is most likely to occur where crosses are made between varieties that are genetically diverse. It is also evident in this Table, the performance of some of these hybrids on basis of yield can justify their immediate use as commercial varieties. This will be possible, only if they combine the high yield with good quality and disease resistance (Dhaliwal Singh T. 1968).

Table1. Some growth and yield characters for selected parents together with cherry yield of the same parents and their F1 hybrids.

\begin{tabular}{lllllll}
\hline Character(1) & \multicolumn{5}{c}{ Parents } \\
\hline & Laurina & Padang & H.d. Timor & K7 & SL28 & SL34 \\
Girth (cm) & 11.09 & 13.31 & 13.21 & 14.33 & 14.72 & 14.61 \\
C. radius (cm) & 15.05 & 43.86 & 47.79 & 50.11 & 53.56 & 52.53 \\
Int. L. Pr (cm) & 1.68 & 3.74 & 4.24 & 4.10 & 4.45 & 4.40 \\
B. Primaries (nr) & 61.94 & 50.00 & 46.59 & 46.37 & 46.05 & 45.53 \\
B. Nodes (\%) & 13.56 & 16.01 & 8.91 & 21.93 & 14.16 & 14.23 \\
Be/node (nr) & 4.24 & 6.52 & 6.17 & 5.63 & 6.11 & 7.88 \\
\hline Yield & Laurina & Padang & H.d. Timor & K7 & SL28 & SL34 \\
Laurina & 2.49 & 6.22 & 6.43 & 6.62 & 5.65 & 5.89 \\
Padang & & 5.86 & 5.58 & 5.24 & 6.53 & 6.69 \\
H.d. Timor & & & 3.77 & 4.83 & 6.76 & 5.67 \\
K7 & & & & 4.16 & 5.49 & 5.21 \\
SL28 & & & & 5.41 & 5.19 \\
SL34 & & & & & 5.64 \\
\hline
\end{tabular}

(1) Girth, Bearing Primaries, Bearing nodes and Berries per node (Be/node) were taken during the second year after field planting; canopy radius, Internode length on primarries, on plants 1V4 years after field planting. Yield, is the mean yield per tree over three years of production. All measurements are means for two plant densities.

In general, if hybrid vigour results mainly from overdominance at the heterozygous loci governing a character (i.e. intrallelic interactions), then there will be no justification in carrying on selection in further generations. Rather, the F1 hybrids themselves can be used for commercial production. If, on the other hand, heterosis is due either to the accumulated action of favourable dominant or semidominant genes dispersed amongst the parents, or to complementary interaction of additive, dominant or recessive genes at different loci (non allelic interactions), then it is worth remembering in principle, that homozygous lines can be derived as good as the $F 1$ 's showing the hybrid vigour. Regarding yield in this review, hybrid vigour observed could be ascribed mainly to complementary epistatic genes (Griffing, J.B., 1956b).

The process of continued selfing in subsequent generations to derive homozygous lines for a tree crop like coffee is prohibitive both in terms of time and expense. However, if high yielding seed varieties have to be produced, then it would be necessary to carry out successive cycles of selection in the F2 and F 3 generations of selfing. In the F2 generation, selection would be on individual plant basis with only the high yielding trees being retained. In the F3 generation, line differences will become apparent and also the level of heterozygosity within each line (Griffing, J.B., 1956a).

Selection would then be for outstanding individual trees in the superior lines and preferably in those lines showing least variation among individual trees. It may be possible for seed obtained from such selected F3 trees to be used for commercial production, though this material will still have some degree of residual heterozygosity. The average performance of this fourth generation however, may be comparable to that of the heterotic F1's and will be well above the average performance of the F2 generation. This is so because, though the number of heterozygous loci will decrease with inbreeding and so is the hybrid vigour, these will be compensated for by accumulation of favourable genes, which might even result in transgression. For such a scheme to be applicable especially in the Kenyan situation, not only have the genotypes released to the farmer to be high yielding, they 
must also be uniform in growth habit, and must carry CBD resistance genes at least on 2 loci or preferably 3 loci in a homozygous state. In addition, they should be resistant to coffee rust (Griffing, J.B., 1956b).

The advantage of hybrid varieties in arabica coffee is that development of such varieties is much more rapid and such hybrids will normally show remarkable uniformity with respect to various characters. Furthermore, such hybrids may show hybrid vigour caused by intra- or inter-allelic interactions. In the breeding programme at the CRS (Ruiru), use of hybrid varieties may be preferred as it will offer a quicker solution to the farmer's problem (van der Vossen, H.A.M. \& D.J. Walyaro, 1981).

\section{Breeding for improved coffee quality}

Normally yield improvement is considered concurrently with coffee quality. Unlike yield however, variation among genotypes for quality characters, as was found in the present review, is mainly due to additive effects of genes. As a consequence, progenies derived from single or multiple crosses involving parents with good quality characteristics will also be expected by and large to give coffee of good quality. Very often however, it becomes necessary to make crosses where one of the parents is lacking in some quality characters. For instance, Rume Sudan (with very small bean size) or Pretoria (with inferior liquor quality). In such a case, it may be necessary to improve the resultant hybrid by making a number of backcrosses to a recurrent parent with better coffee quality, or crossing the hybrid to a different parent having both better coffee quality and possibly other desirable attributes (Thorold, CA., 1987).

In the case of a backcross scheme, it is advisable for the number of backcrosses to be restricted to 1 or 2 ; otherwise in a perennial crop with a long juvenile period, it can be time consuming. In any case, because of the high heritability of the quality characters, selection in later generations derived from such backcrosses will still give opportunity for further improvement. Evaluation of quality in each generation can be done during the first one or two years of production and will be based on coffee samples derived normally from a number of trees per progeny. In improvement of bean size and liquor quality, selection should be restricted to genotypes having a high $\%$ bold bean (disregarding \% small), and a good overall standard. In making crosses between various parents, it is also worth noting that reciprocal differences especially for bean characters may occur. Because of this, it is advisable in general to use genotypes with better bean size as the female parents, rather than vice versa (Thorold, CA., 1987).

There were a number of F1 hybrids in this review with good bean size, and satisfactory liquor quality which also happened to be very productive. Among such hybrids for example are those derived from crosses of Padang and SL34, Padang and SL28, and Laurina and K7. Clearly such hybrids would be most suitable for the programme of hybrid variety production discussed in section 2 . Unfortunately none of these hybrids show a satisfactory level of disease resistance. In other words, these F1 hybrids have to undergo further hybridization with disease resistant varieties before they can be considered suitable for commercial use (Thorold, CA., 1987).

\section{Compact growth characters}

For requirements of modern agriculture compact plant types are often preferred because in general, they tend to be more suitable for planting at higher densities. As a consequence, not only is production per unit area of land increased but also if desired the total area under a certain crop may be reduced to release extra land for production of alternative crops, which may be of equal value to the farmer. This aspect is especially relevant to Ethiopia where the majority of the coffee is produced in the high potential areas which happen also to be ideal for production of food crops. Because there is an increasing demand for food production due to the high population growth, coffee in this respect, is in direct competition with food crops (van der Vossen \& Walyaro, 1981).

In arabica coffee, genes confering compact growth can be found in varieties with reduced plant size, like 74110, 74112, 74140, 74148, 7458, 74165, Caturra, San Bernardo, Turrialba Compact, Laurina and Mokka, or in varieties with lateral branches which are more or less orthotropic, for instance Erecta and Semi erecta. In Caturra, Turrialba Compact and San Bernardo, the character displays for practical purposes almost complete dominace whereas in Laurina it is semi-recessive or recessive. In addition Laurina is highly unproductive probably because of having extremely short internodes on the laterals. This variety seems to be of little use in breeding programmes for compact growth. Laurina however is a valuable parent due to its good combining ability for yield and quality (Thorold, CA., 1987).

The compact growth character as occurs in Caturra is extremely useful in breeding programmes. Apart from being dominant and showing complete penetrance, the character is probably monofactorial (Carvalho, 1958a) and hence easy to manipulate. It can be used for instance, in deriving homogeneous compact plant types even though the genotypes may be heterozygous at loci controlling other characters. In production of hybrid varieties, use of plants homozygous for the Caturra gene as one parent, automatically ensures that all hybrids will be uniformly compact. Caturra in this study also appears to impart remarkable stability for compact growth habit to most of its F1 hybrids in environments of increased plant density (Mitchell, H.W., 1976).

One drawback with Caturra in this study is that most of its $F 1$ hybrids were not that outstanding in yield 
performance, especially in their response to high plant density. Some of these compact genotypes appeared to be even more sensitive to increased plant competition than some of the tall genotypes. As a consequence, most progenies of crosses involving Caturra as one parent did not display marked hybrid vigour to the extent of that observed in a number of other parental combinations at the higher density. The use of Caturra in single hybrids therefore may not produce anything better in terms of yield than the present commercial varieties, especially when planted at higher densities. It is expected on the other hand, that the new compact varieties to be eventually developed should represent plant types that are at least more productive at higher plant densities than the varieties presently grown commercially. Nonetheless, Caturra can still be improved through hybridization and further selection. For example the material like Catimor, selected F 3 or F 4 genotypes from a cross between Caturra and Hibridode Timor, is in many respects superior to Caturra or even its F1 hybrids (Mitchell, H.W., 1976).

Aside from individual tree yield of compact genotypes, their growth habit from the farm management point of view is very attractive. Training (capping) of such trees is unnecessary and pruning is restricted to removing the lowest branches which touch the ground. Furthermore, picking on such genotypes will be relatively easy, and cases of breakages of the main heads, as often occurs with tall varieties carrying a heavy crop or during picking, will be considerably lessened. The only obstacle in such densely planted coffee is that it will be much more difficult to control CBD and rust unless such genotypes also carry resistance to these two diseases (Browning, G. \& N.M. Fisher, 1976).

Combining compact growth of the type of Caturra with new improved genotypes is an easy procedure. Selection for compact types is even more facilitated in that it can be performed on seedlings about 1 year old in the nursery. This also helps the breeder to cut down on the number of plants eventually to be planted in the field. Regarding breeding for genotypes with more erect branching pattern, evaluation for this character can also be done on seedlings in the nursery. The performance of $F 1$ hybrids derived from Erecta as one parent, in this review was in many cases also rather disappointing especially for yield. A few hybrids however, showed good yield stability. This character at the present moment does not seem to merit such serious attention in breeding programmes as compared to other more important characters like disease resistance, yield and quality. It could however be considered in later stages of such breeding programmes (Carvalho, A., 1958).

\section{Disease resistance}

In the breeding programme at the CRS, Ruiru and JARC and in many other breeding institutions for arabica coffee, disease resistance receives more attention than any of the characters that have so far been considered. Resistance in arabica coffee is sought to 2 main diseases, coffee berry disease, and coffee rust. No detailed treatment of this subject will be given here, all that is considered is a simplified scheme on how disease resistance can be combined with compact growth, yield and quality in a breeding programme (van der Vossen \& Walyaro, 1981).

Breeding for resistance to coffee rust involves programmes to transfer vertical resistance genes, and/or horizontal resistance governed by polygenes, to new varieties being developed (Rodrigues et al. 1975 and Monaco 1977). Regarding coffee berry disease, the programme at the CRS Ruiru, aims at introducing resistance by also making use of a number of major genes (van der Vossen et al, 1976; van der Vossen \& Walyaro, 1981). Though there is circumstantial evidence that such resistance to CBD may be of a stable nature (Masaba, 1981), it is thought however, more advisable to accumulate in one genotype as many resistance genes as possible to enhance the stability. The CBD resistance genes have been designated (van der Vossen \& Walyaro 1981) as: the dominant $R$ and the recessive $\mathrm{ft}$-both found in variety Rume Sudan, theft-gene also occurs in variety K7. Hibrido de Timor carries one resistance gene on the $T$-locus, with intermediate action. In addition as was mentioned earlier, this variety is also resistant to most physiologic races of coffee rust. Such a gene or a complex of genes will be designated $H T$, for illustrative purposes. The breeding scheme is aimed at developing compact varieties with at least 3 resistance genes to CBD plus resistance genes to coffee rust (van der Vossen, H.A.M. \& D.J. Walyaro, 1980).

For the purpose of illustration 4 varieties are used, Rume Sudan, SL28, Hibrido de Timor and Caturra. Two alternative schemes are also given in Figure 1 and 2 respectively, for a programme of hybrid variety production, and one suitable for production of seed varieties. The scheme starts with making crosses between Caturra and Hibrido de Timor, to combine the CBD $T$-gene, Leaf rust resistance, with the compact $C t$ gene of Caturra. Rume Sudan is crossed to SL28 to introduce the $R$ - and $\mathrm{ft}$ - genes into the other F1 hybrid. As can be seen in Fig 1 , it is fairly easy to select from the F2 generation a genotype homozygous especially for the $T$-, $C t$ - and $H T \sim$ genes on basis of the progeny test performed on seedlings obtained from the selfed F2 generation. Because such a genotype is represented only once out of 64 invididuals it is advisable to raise large number of F2 seedlings. However, F2 seedlings susceptible to CBD can already be discarded on basis of the preselection test for CBD resistance (van der Vossen et al, 1976), and noncompact seedlings can also be discarded while still in the nursery (see section 4.). Eventually only about $40 \%$ of the F2 's will be planted in the field, and on screening for leaf rust resistance on young plants in the field, using the leaf disc inoculation test (Eskes et al., 1983), about only 30\% of the initial number of F2 's raised will remain to be selfed for progeny tests. 
ISE

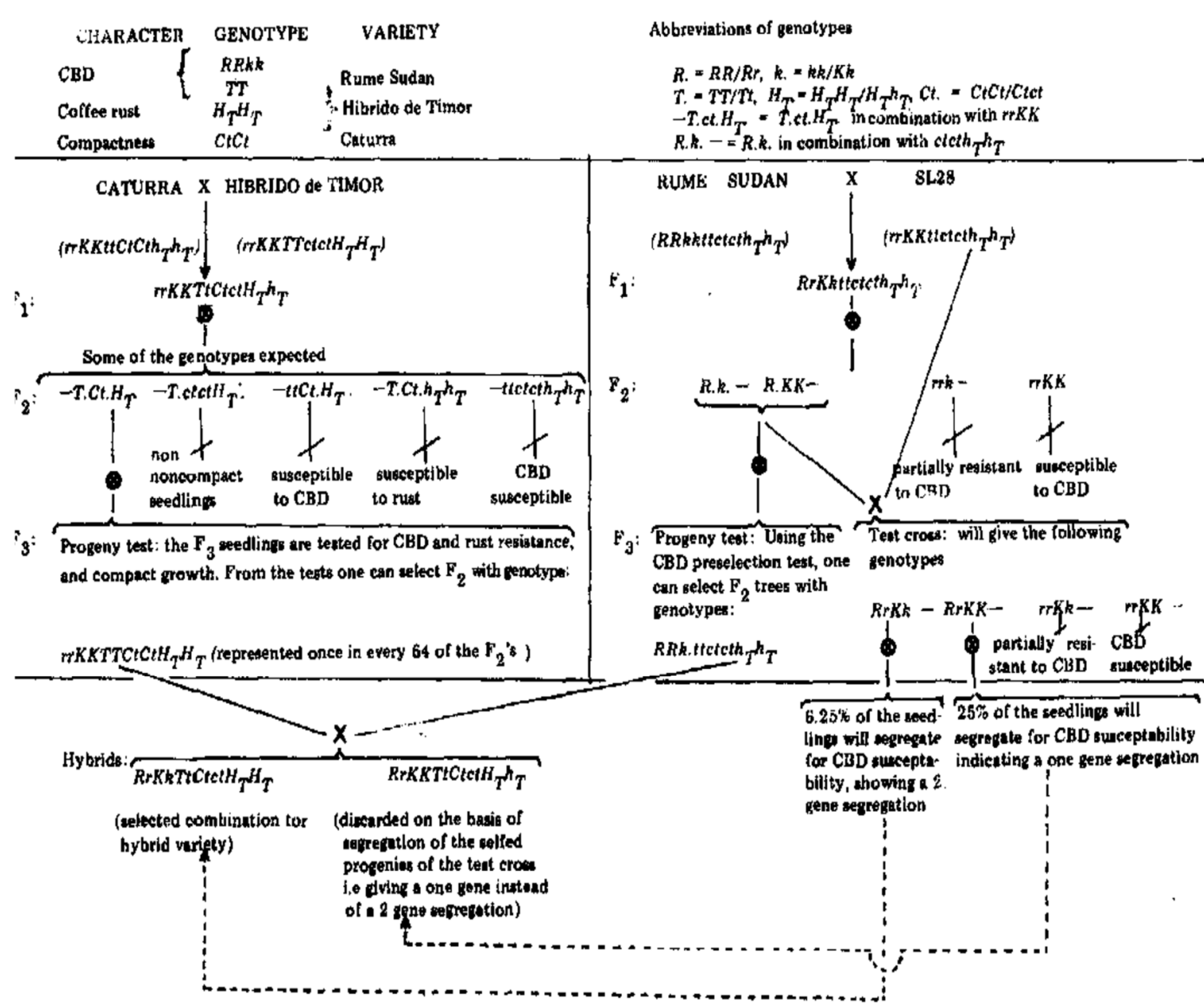

Fig. 1: Alternative scheme for deriving hybrid varieties

Regarding fixing of the $R$ - and $k$ - genes in the other hybrid this will depend mainly on the preselection test for CBD resistance. As indicated in Fig 1, it will be necessary also to perform a test cross in order to distinguish F2 individuals carrying the 2 genes in a homozygous state from those carrying only one gene. The resistant F2 individuals are crossed to a susceptible variety e.g. SL28 and SL34 and the seedlings raised are preselected for CBD resistance. From these results it is possible to distinguish immediately F2 plants homozygous for the $k$-gene but heterozygous for the $R$ - gene, because the $k$ - gene is partially recessive. To discover F2 genotypes carrying the $R$ - gene in a homozygous state, will require seedlings raised from the testcross to be planted out in the field and eventually on flowering, to be selfed. It is on basis of results obtained from the CBD preselection of these seedlings that F2 individuals homozygous for one $R$ - gene can be distinguished from those with 2 resistance genes (RRkk) (van der Vossen et al, 1976).

However from results of CBD preselection performed on seedlings obtained from selfed resistant F2 plants it is already possible to select those F2 's carrying $R R K$ - or $R R k k$. Such plants when crossed to genotypes homozygous for the $H_{T^{-}}, C_{t^{-}}$and $T$ - genes, will give hybrids having CBD resistance on 2 or 3 loci. Combining ability of the individual trees selected in each of these two groups in terms of other characters e.g. yield and quality can then be evaluated in- trials, involving these hybrids. When the final results of CBD preselection on progenies of the test crosses eventually become available, it is then possible to discard the F2 trees in this group with genotypes $R R K K$ or $R R K k$. The remaining best combining F2 trees with genotypes $R R k k$-, in one group, and TTCtCtHTHT, in another group, will then be used for production of hybrid varieties through artificial cross pollination (van der Vossen et al, 1976).

An alternative scheme involves making four way crosses i.e. (Caturra $\mathrm{x}$ Hibrido de Timor) $\mathrm{x}$ (Rume Sudan $\mathrm{X}$ SL28). The progenies of such a cross will be preselected for CBD resistance discarding susceptible seedlings i.e. carrying $r r K k t t-, r r K K t t$-, and of the remaining seedlings, those having noncompact growth (-ctct) as observed in the nursery. While in the field, they will also be screened for leaf rust resistance. The remaining selected plants will be selfed and the progeny will again undergo these screening tests. On basis of segregation of these progenies for CBD resistance, it will be possible to distinguish individuals of the initial four-way cross carrying at least 3 CBD resistance genes. Such genotypes, carrying the genes RrKkTt in combination with Ctct $H T h T$ will occur only 
once in every 32 non-discarded F1 individuals. The selfed progenies of these $F 1$ individuals will form the $\mathrm{F} 2$ generation, and those selected in this generation for disease resistance and compact growth will in turn also be selfed to form the F 3 generation (van der Vossen et al, 1976).

After discarding susceptible and non compact F3 seedlings, the remaining seedlings will be planted in the field again to be screened for coffee rust. On flowering, the selected F3 individuals will be selfed and also testcrossed to a susceptible variety. Progenies of selfed F3 individuals will be screened for CBD resistance, compact growth and eventually also, rust resistance. On basis of these results, only F3 individuals whose selfed progenies show no segregation with respect to all the above characters will be selected. Regarding seedlings of the testcross, these will first be screened for CBD, in order to distinguish F3 individuals carrying the $k$ - gene alone in homozygous state. The resistant seedlings of the test cross will be planted in the field and on first flowering will be selfed. On basis of segregation during the CBD preselection of the seedlings of the selfed plants from the testcrosses, individuals in the F3 generation carrying 1 or 2 CBD resistance genes can be discarded together with their F4 progenies (Van der Vossen, H.A.M. \& D.J. Walyaro, 1980).

Seed varieties can then be selected among remaining F3 or F 4 material, homozygous for the 3 CBD resistance genes and for rust resistance as well as homozygous for $C t$ - gene for compact growth. As would be expected, the scheme aimed at producing seed variety (see Fig 2) takes a considerably longer time, than that for producing hybrid varieties (see Fig 1) though in the end multiplication of seed for the farmers is a lot easier (van der Vossen, H.A.M. \& D.J. Walyaro, 1980).

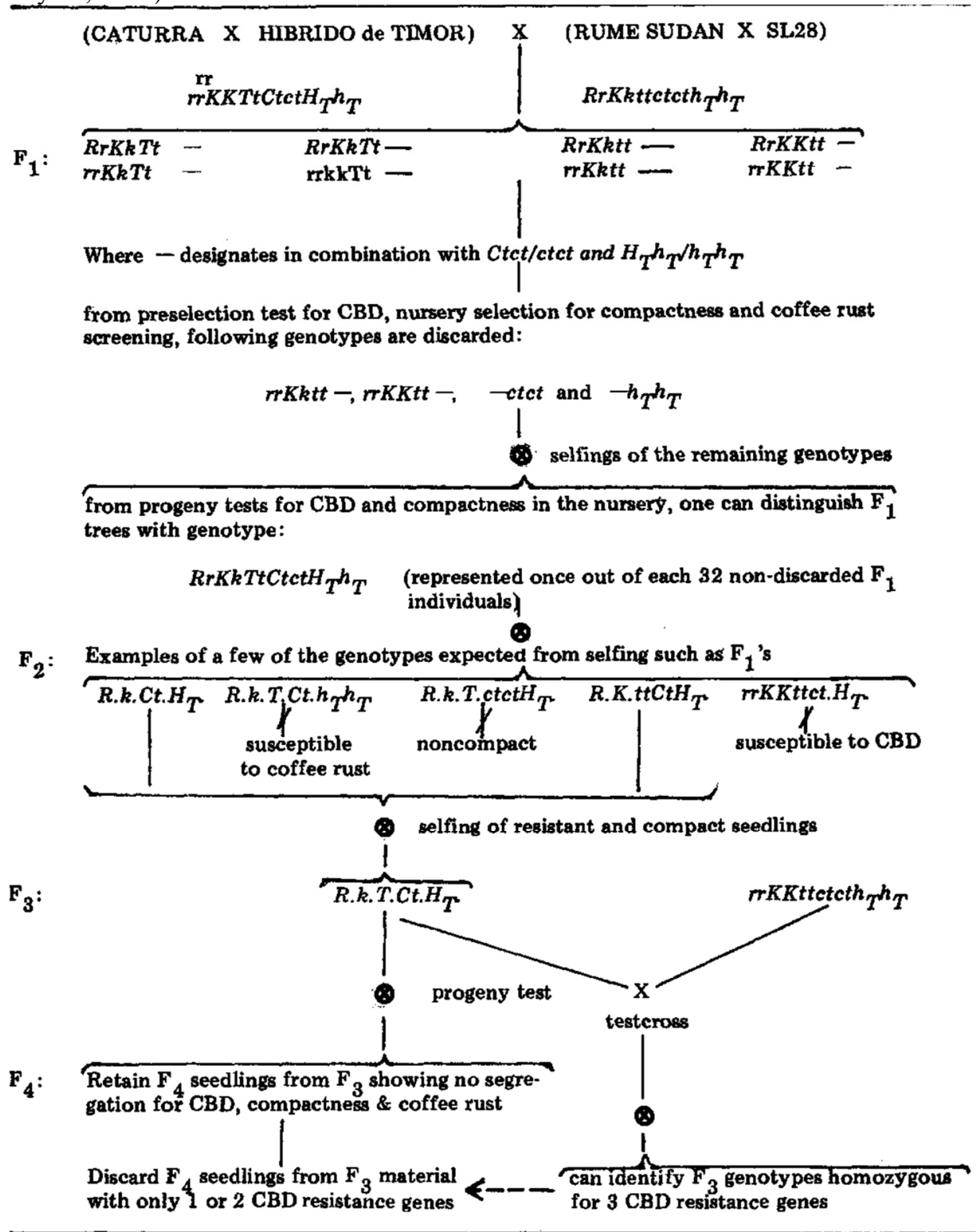

Fig. 2: Alternative scheme for deriving disease resistant and compact seed varieties. 
In the above scheme, apart from progeny tests, test crosses have had to be used. This is so because, whereas it is easy to distinguish through progeny tests a genotype with two CBD resistance genes e.g. $R r K k$ from that with only one resistance gene $R r K K$, it is not easy to differentiate the genotype $R R K K$ from $R R K k$ by the same procedure. As indicated earlier, the $R$ - gene is dominant and imparts a high level of CBD resistance whereas the $\mathrm{ft}$ - gene is partially recessive imparting a relatively low level of resistance. If the last two genotypes were progeny tested, $R R K K$ would reproduce itself and all progenies would be resistant. $R R K k$ would give $R R K K, R R K k$ and $R R k k$ and these progenies, on average would have a relatively higher level of resistance compared to those with the genotype $R R K K$. In practice however, the difference in the level of resistance between these two sets of progenies may be so marginal that there may be difficulties in distinguishing which of the original genotypes had two resistance genes. If on the other hand, the two genotypes were testcrossed thus: $R R K K x \operatorname{rrKK}$ to give $R r K K$, and $R R K k \mathrm{x}$ $r r K K$ to give $R r K K, R r K k$ followed by selfing these progenies i.e. $R r K K$ and ( $R r K K, R r K k$ ), the proportions of true susceptible seedlings would be the best indicator of the number of resistance genes carried in the original genotypes. A similar situation would also arise for example in the case of genotypes $R R K k$ and $R R k k$ (Van der Vossen, H.A.M. \& D.J. Walyaro, 1980).

Finally it is worth mentioning that resistance to coffee rust in Hibrido de Timor was regarded for ease of presentation in this scheme, as a single factor. Some evidence suggests that this resistance may be conditioned by a number of genes. In view of limited information available about the nature of each specific gene, in selection, rust resistance of the Hibrido de Timor type, can still be regarded for practical purposes as one complex factor. In any case, provisions are contained in the proposed Scheme for progeny testing the immediate parental genotypes before their progenies can be recommended for use by the farmers (Rodrigues Jr. C.J. \& A.J. Betterncourt, 1965).

Breeding for stable resistance to coffee rust would entail including also sources of horizontal resistance in such a programme. This is possible if one of the varieties included in the programme also shows some horizontal resistance. In this case for example Rume Sudan. Leaf disc inoculation test is able to distinguish to some extent, reaction due to horizontal resistance (a long latent period after infection) from that due to vertical resistance (showing complete absence of infection). Using such a technique it is possible to select initially, in the progeny of one set of crosses, genotypes with a high level of horizontal resistance and cross these eventually to those selected for vertical resistance. Hybrid seed from such crosses would give genotypes carrying genes both for vertical and horizontal resistance. For a seed variety breeding programme, further selection for horizontal resistance within later generations of selfing may be complicated in the presence of vertical resistance genes. When practicing selection however, instead of discarding genotypes showing horizontal resistance, they should be retained so as to end up eventually with a population of genotypes having vertical resistance but also with some level of horizontal resistance (Gabriel, C \& B. Pablo, 1980).

\section{REFERENCES}

Baker, R.J., 1978. Issues in Diallel Analyses. Crop Sei. 18: 533-536.

Browning, G. \& N.M. Fisher, 1976. High density coffee: yield results for the first cycle from systematic plant spacing designs. Kenya Coffee 41 (483): 209-217.

Carvalho, A., 1958. Coffee genetics and breeding. Bull. Inst. Agron. Campinas, Brasil, 13 p.

Dhaliwal Singh T. 1968. Correlations between yield and morphological characters in Puerto-Rican and Columnaris varieties of Coffea arabicaL. J. Agric. Univ. Puerto Rico 52(1): 29-37.

Eskes, A.B. 1983. Incomplete resistance to coffee leaf rust (Hemileia vastatrix). Doctoral thesis Agric. Univ. Wageningen, The Netherlands, $140 \mathrm{pp}$.

Fernie, L.M., 1961. Selection and breeding programmes in Lyamungu. Mimeo report 14 p + 3 Appendices.

Gabriel, C \& B. Pablo, 1980. Horizontal resistance expression to rust (Hemileia Vastatrix B. \& Br.) in Coffea canephora Var. Conilon. Presented to the 9 Int. Scient. Coll. Coffee (London, 16 June - 20 June 1980). ASIC.

Griffing, J.B., 1956a. A generalised treatment of diallel crosses in quantitative inheritance. Heredity 10: 31-50.

Griffing, J.B., 1956b. Concept of general and specific combining ability in relation to diallel crossing systems. Austral J. Bio. Sei. 9: 463-493.

Masaba, D.M., 1981. Evidence of cork barrier formation as a reistance mechanism to coffee berry disease (Colletotrichum coffeanum Noak sensu Hindort) in arabica coffee. J. PI. Path. 88:19-32.

Mitchell, H.W., 1976. Research on close-spacing systems for intensive coffee production in Kenya. Ann. Report 1974/75 Coffee Res. Found. Kenya 13-57.

Rodrigues Jr. C.J. \& A.J. Betterncourt, 1965. Routine Screening for resistance to Hemileia vastatrix B. \& Br. on Coffea arabica L. accessions from different coffee producing regions of the World. Centr. Inv. Ferrug. Caf. Prog. Rept. 1960-1965: 47-99.

Srinivasan, CS., 1980. Association of some vegetative characters with initial fruit yield in coffee (Coffea arabica L.) J. Coffee Rs. 10 (2): 21-27.

Thorold, CA., 1987. A study of yields, preparation out-turns and quality in Arabian Coffee. Emp. exp. Agric. 15: 96-106,167-176. 
Van der Vossen, H.A.M. \& J. Op de Laak, 1976. Large scale rooting of softwood cuttings of Coffea arabica in Kenya. I Type of propagator, choice of rooting medium and type of cuttings. Kenya Coffee 41: 385-399.

Van der Vossen, H.A.M., R.T.A. Cook \& G.N.W. Murakaru, 1976. Breeding for resistance to coffee berry disease caused by Colletotrichum coffeanum Noack (sensu Hindorf) in Coffea arabica L. I Methods of preselection for resistance. Euphytica 25: 733-745.

Van der Vossen, H.A.M. \& D.J. Walyaro, 1981. The coffee Breeding Programme in Kenya: A review of progress made since 1971 and plan of action for the coming years. Kenya Coffee 46:113-130

Van der Vossen, H.A.M. \& D.J. Walyaro, 1980. Breeding for resistance to coffee berry disease in Coffea arabica L. II. Inheritance of the resistance. Euphytica 29: 777-791. 